\title{
Identification of Barriers and Productive Zones Using Reservoir Characterization
}

\author{
Attia M. Attia ${ }^{1}$ and Habibu Shuaibu ${ }^{2}$ \\ Petroleum Engineering and Gas Technology, British University in Egypt, Cairo, Egypt ${ }^{1,2}$
}

\begin{abstract}
The most common complication faced by petroleum engineers is the description of a reservoir, both accurately and efficiently. Inadequate and insufficient reservoir characterization lead most enhanced oil recovery and secondary recovery projects to fail and also makes it difficult to deal with heterogonous reservoir. An accurate description of a reservoir is vital to the reservoir management and achieving maximum oil recovery. Reservoir characterization plays a very important role in descripting the storage and flow capacity of a reservoir and also plays a decisive role in reservoir simulation. The main objective of this research is to identify reservoir barriers and productive zone using reservoir characterization, in this study some of the most useful methods such as Flow Zone Indicator (FZI), Discrete Rock Type (DRT), Winland R35 methods were applied to 4 different wells to identify the rock types and flow units developing a static reservoir characterization model. To achieve the objective of this research the static model is transformed into a dynamic model by introducing graphical method such as stratigraphic flow profile (SFP), stratigraphic modified Lorenz plot (SMLP) and modified Lorenz plot (MLP) to easily quantify reservoir flow units based on physical structure, storage capacity, flow capacity, rock type and reservoir process speed. The physical structure permits the flow units to be interpreted in a stratigraphic model arrangement, determining well-to-well correlation schemes; the main aim of understanding the flow unit's characterizations is to identify the barriers, speed zones and baffles.
\end{abstract}

Keywords: Flow Zone Indicator (FZI), Discrete Rock Type (DRT), Winland R35 methods, Flow unit (FU), Reservoir Quality Index (RQI), Hydraulic Flow Unit (HFU) stratigraphic flow profile (SFP), stratigraphic modified Lorenz plot (SMLP) and modified Lorenz plot (MLP).

\section{INTRODUCTION}

Reservoir characterization plays a fundamental part in all oil and gas industry, the understanding of the reservoir rock properties such as porosity; permeability and pore throat assists engineers improve reservoir characterization. Reservoir characterization is described as the manner of quantitatively character reservoir using the available data. Heterogeneous reservoirs usually present high challenges to engineers and geologist in acquiring accurate of the hydraulic flow unit, rock typing, barriers and productive zone performance and recovery predictions, because of its tendency of being tight and heterogeneous.

For numerous ages petroleum engineers and geoscientists have studied and introduced methods to advance the reservoir characterization as it has remained a difficult encounter, reservoir characterization methods are entirely valued because they bring a much better-quality and exact characterization of the storage and flow capacity of an oil and gas field and consequently offerings a foundation for developing a simulation model.

Hydraulic flow unit (HFU) defines the division of reservoir channels towards different zones with the same flow and bedding characterization, thereby integrating factors like porosity and permeability towards a solo magnitude that defines a formation, indicating flow zones and rock typing.

Rock type is a key concept in improving the reservoir description of straddles multiple scales and bridges multiple disciplines. Reservoir rock classification (rock

typing) has been a fundamental tool for reservoir characterization, several techniques introduced by several authors has been used to identify rock types in a formation such as FZI, DRT and winland (35), that indicates different flow zones (HFU) for each dissimilar rock type.

Parameters involved in these techniques are usually obtained from core data analysis, well logs and well tests, thus in this studies the core data analysis is being used. However, it is difficult predicting properties for uncored well.

Flow unit is described as stratigraphic uninterrupted interval of the same reservoir process speed that respects the physical structure and retains characteristics of the rock type. Graphical method is a tool using to determine flow units using techniques such as stratigraphic flow profile (SFP), stratigraphic modified Lorenz plot (SMLP) and modified Lorenz plot (MLP) to quantify reservoir flow units based on physical structure, rock and pore throat types, reservoir speed process and flow and storage capacity of the reservoir creating stratigraphic model correlation.

The key purpose of this research is to describe the rock type, flow zones and flow unit characterization to identify barriers (seals), baffles (zones control fluid flow) and speed zones from 4 wells of an Egyptian reservoir. Provided an enhanced characterization of the reservoir.

\section{BACKGROUND THEORY}




\section{A. HYDRAULIC FLOW UNIT}

This method describes the quality of an entire reservoir rock in which the geological properties (texture, mineralogy, sedimentary structure, bedding) and petrophysical properties (porosity, permeability, capillary pressure) that affect fluid flow are surely predictable and certainly dissimilar from properties of different rocks. Each flow unit/zone in the reservoir represents a continues lateral, vertical and similar flow and bedding characteristic. In this approach rock types are classified based on the equation below:

$$
R Q I=0.0314 \sqrt{\frac{K}{\varphi_{e}}}
$$

Where $\varphi_{e}$ is effective porosity (fraction), $\mathrm{K}$ is permeability (md) and RQI is rock quality index $(\mu m)$. Additionally, core derived porosity must convert to normalize one as shown below:

$$
\varphi_{z}=\frac{\varphi_{e}}{1-\varphi_{e}}
$$

Where $\varphi_{z}$ is normalized porosity. Lastly Flow zone indicator can be calculated by the equation below:

$$
\log R Q I=\log \emptyset_{Z}+\log F Z I
$$

On a log-log plot of RQI versus $\emptyset_{z}$ will be plotted, core samples with the same pore and grain size characteristics will lie on a straight line with a unit slope, while core samples with dissimilar FZI will lie on different parallel lines. To assist in simplifying the use of rock type in a recreation model, continued FZI values are transformed to discrete rock type (DRT) by equation using the equation below, so as to assist calculate the permeability of each geological model using permeability-porosity relationship of each discrete rock type.

$$
D R T=\text { Round }(2 \ln (F Z I)+10.6)
$$

\section{B. Winland Method (R35)}

For several years' scientist have made experiments using capillary pressure curve by mercury injection to estimate pore throat sizes. In this approach, developed an experimental correlation that relates porosity, permeability and pore throat radius from mercury intrusion tests. The experimental connection of the maximum numerical relationship was attained at the $35 \%$ of the cumulative mercury saturation curve, which is donated as (R35). R35 has been considered to estimate the point where the model pore aperture happens, and it is referred to as the point where the pore system is connected creating an on-going route through the core sample. The winland equation is:

$$
\log (R 35)=0.732+0.588 \log (K)-0.864 \log (\varnothing)
$$

Where $\mathrm{K}$ is the permeability, $\varnothing$ is the porosity and R35 is the calculated pore throat radius at $35 \%$ mercury saturation.

With this in mind confirmed that this case is only correct if the pore throat size is equivalent to the point of inflexion of the pore throat size verse mercury saturation. R35 of a particular rock type will always have the same values. Below are the five-petrophysical flow units with distinctive reservoir performance differentiated by the extension of the R35 standard:

- Mega-porous units, expressed by R35 greater than 10 microns.

Macro-porous units, expressed by R35 between 2.5 and 10 microns

Meso-porous units, expressed by R35 between 0.5 and 2.5 microns

Micro-porous units, expressed by R35 between 0.2 and 0.5 microns

- Nano-porous units, expressed by R35 smaller than 0.2 microns

\section{Graphical Methods}

These methods introduce tools which support easy description of reservoir flow units established based on storage capacity, flow capacity, flow unit speed with relation to determined rock types using techniques such as winland R35, FZI, and DRT. Determined rock types are transformed to petrophysical established flow units, which can be entered in a statistical flow simulator. Application of these methods begins by determining the rock types within a physical structure; the physical structure permits the flow units to be interpreted in a stratigraphic model arrangement, determining well-to-well correlation schemes. The main aim of understanding the flow unit's characterizations is to identify the barriers, speed zones and baffles. The three graphical tools used to determine flow units are:

\section{Stratigraphic Modified Lorenz Plot (SMLP)}

This tool is a plot of computed percent flow capacity versus percent storage capacity in a stratigraphic sequence, which display a shape illustrating the flow performance of each zone.

\section{Stratigraphic Flow Profile (SFP)}

In this tool a flow profile is created, displaying the correlation of an interpreted flow unit consisting of Gamma ray (GR), porosity and permeability (core data), winland R35, K/Phi, percent flow capacity and percent storage capacity. This flow profile is the foundation that compares flow units from different techniques to develop a 3 dimensional flow unit reservoir description and a flow unit interval can be developed in respective to winland $\mathrm{R} 35$ and K/Phi ratio.

\section{Modified Lorenz Plot (MLP)}

This tool is a plot of percent flow capacity versus percent storage capacity that is computed from flow unit interval obtained from SFP, sorted and plotted in descending order of the flow unit speed. This plot is uncertain to maintain similar traces as the original un-interpreted Lorenz plot .

Furthermore, the shapes of this curve indicates a predictable flow performance of the reservoir, the shape of the curve can be classified into three segment as mentioned below:

- Speed Zone Unit (SZU): These are a steep slope segments that indicates a high degree of percentage of flow capacity corresponding to storage capacity of reservoir. 
- Baffles: These are segments having relatively flat slope FIG 1(A, C, E, G) shows the plot of RQI and normalized indicating very high degree of storage capacity with porosity based on FZI value. As illuminated in this figure, small amount of flow capacity, which is also referred to zone that control formation fluid movement.

Barriers: These are segments that neither have flow nor storage capacity in the reservoir.

\section{III.DATA USED}

The following data is a core sample extracted from 4 different wells of an Egyptian field, consisting of gamma ray (GR), porosity and permeability with depths of each well. Before running this research, the quality of all the samples were checked, a few samples were broken or unavailable due to miss handling of core samples; Fig. 1(B, D, F, H) illustrates the plot of permeability

therefore, they were not included in our calculations to versus porosity classified based on FZI.

ensure accurate readings only.
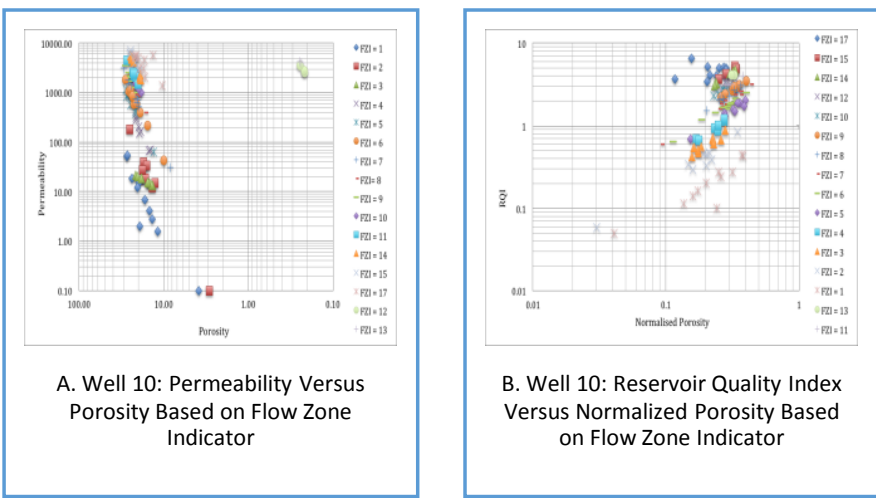

B. Well 10: Reservoir Quality Index Versus Normalized Porosity Based on Flow Zone Indicator
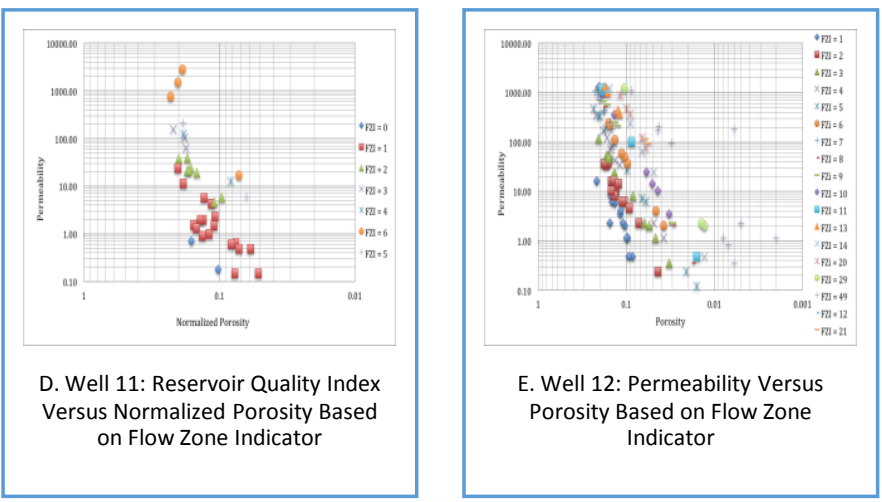
all data laying in the same colour presents accurate straight-line correlations with unit slope of equal FZI value as shown in Table 1.

According to the data in this figure, the well (A10, A11, A12 and A13) display 16, 7, 18 and 14 FZI respectively that confirms the number of HFU in each well; this could be because of the heterogeneity of the reservoir. It is also due to know that rock type with the highest FZI value has the better quality of fluids flow in the pore spaces of the reservoir rock.

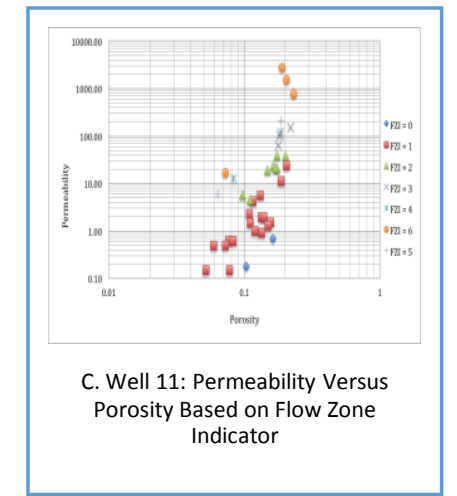

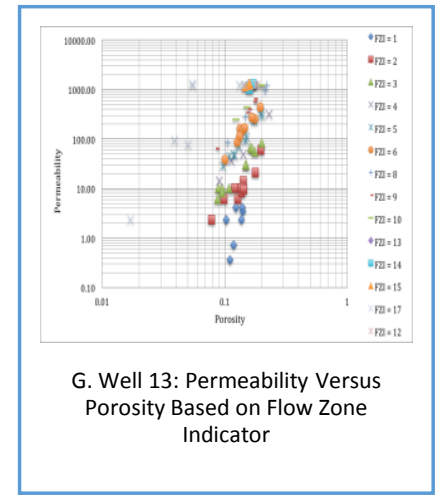

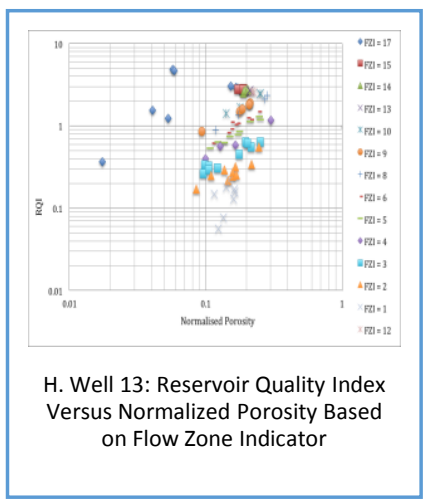

Figure 1: Flow Zone Indicator Results For All Wells

\section{IV.RESULTS AND DISCUSSION}

\section{A. FLOW ZONE INDICATOR (FZI)}

\section{B. DISCRETE ROCK TYPES}

Fig 2 (A, B, C D) shows a plot of permeability versus porosity based on DRT values for all wells, according to 
the data in this figure, the well (A10, A11, A12 and A13) display 9, 6, 10 and 9 DRT respectively.
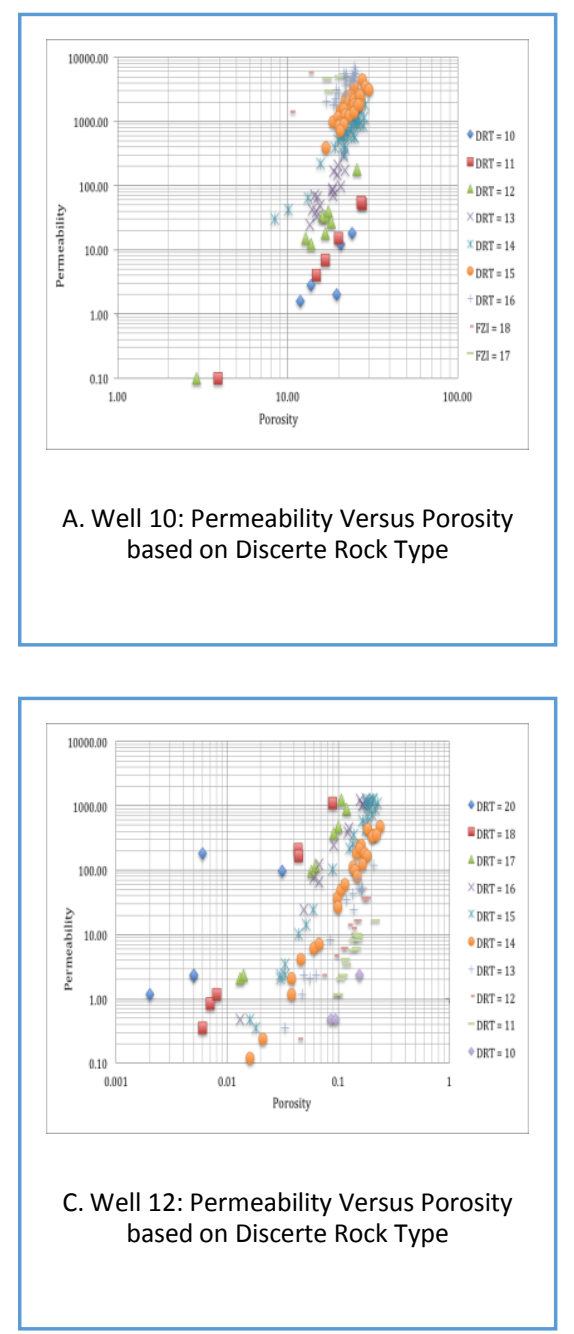

Figure 2: Discrete Rock Type Results for All Wells consuming results. Also, the DRT values have a correlation in each well with similar DRT values that indicates the connection of all 4 wells.
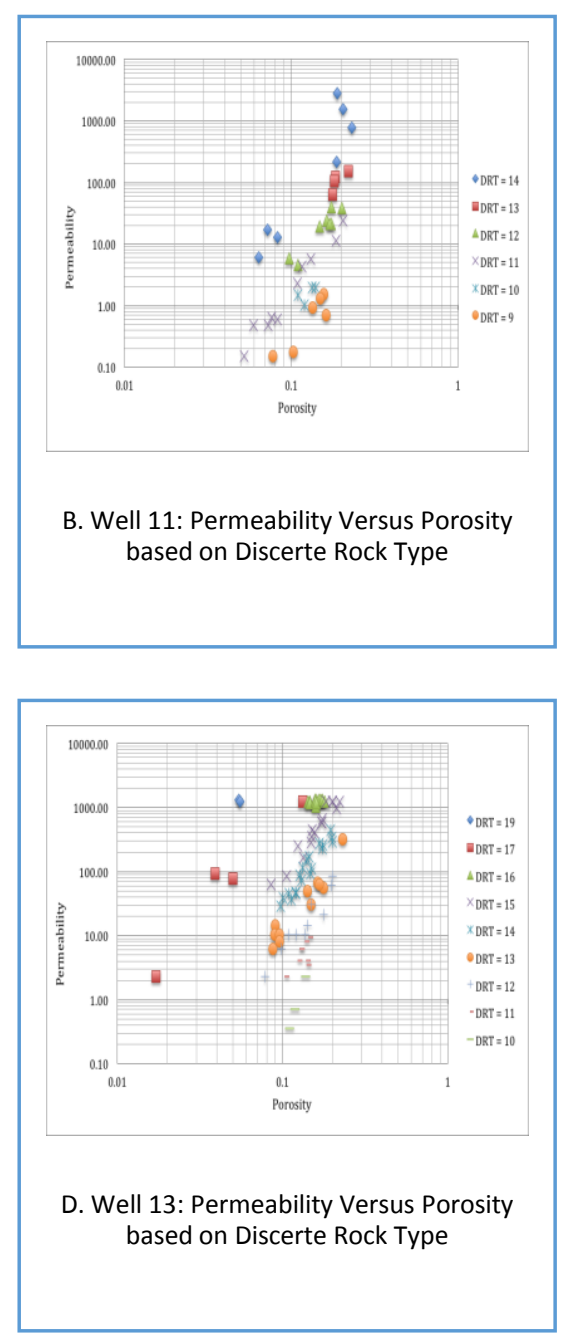

porous and Meso-where classified into two (Marco-porous

\section{WINLAND METHOD} Routine core data gathered for each well was calculated and Meso-of R35 $(1,2,3,4)$ as shown in this figure, as
using winland equation, winland R35 plot of the entire 4 observed in both FZI and DRT, rock types with the highest wells shown in Figure 3 (A, B, C, D), illustrates the core value of pore throat radii have the better quality index to data covers two parts of the plot surface that means the flow fluids through porous media. In addition to winland, existence of separate rock types. Following the winland Figure 10 illustrates the plot of permeability and porosity categories, the 4 wells where classified into two (Marco- based on winland R35 category method. porous and Meso- where classified into two (Marco-
As illustrated in this Figure DRT simplifies the flow units in order to make an easier application of rock type in the simulation models for a more accurate and less time 
D. GRAPHICAL TOOLS: STRATIGRAPHIC FLOW between Gamma ray (GR) logs, porosity and permeability PROFILE (SFP), STRATIGRAPHIC MODIFIED (core data), winland R35, K/Phi ratio and percent of both LORENZ PLOT (SMLP) AND MODIFIED LORENZ flow and storage capacity. This profile is the foundation PLOT (MLP)

1. Stratigraphic Flow Profile (SFP) for comparing flow units to balance wells within a prepared stratigraphic framework to develop a 3 Figure $(4,5,6,7)$, demonstrates a stratigraphic flow Furthermore, flow units' interval is defined in respect to profile showing the correlation and inter-relationship $\mathrm{K} / \mathrm{Phi}$ ration and winland R35 for each well 
International Advanced Research Journal in Science, Engineering and Technology Vol. 2, Issue 12, December 2015

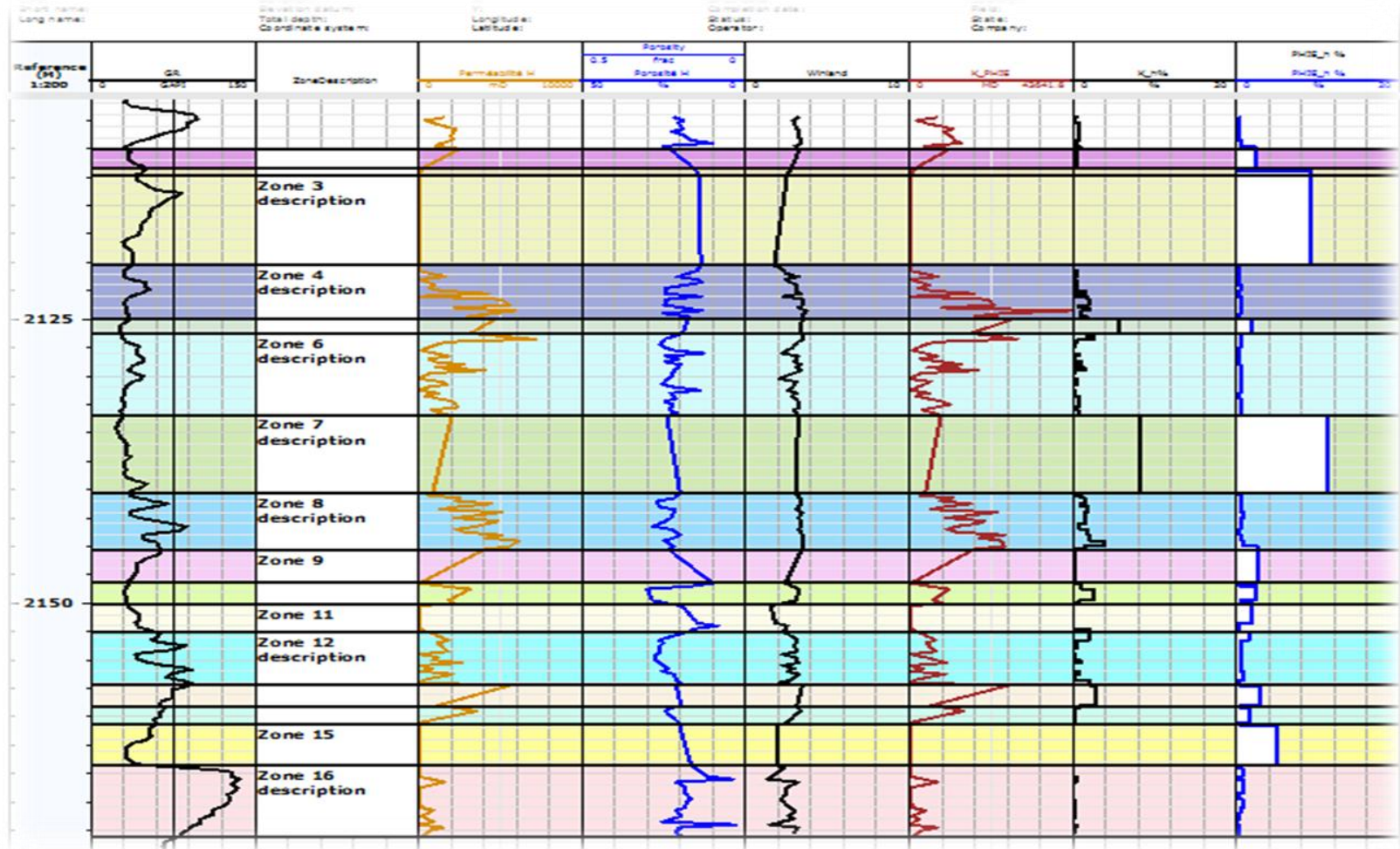

Figure 4: Well 10 Stratigraphic Flow Profile (SFP)

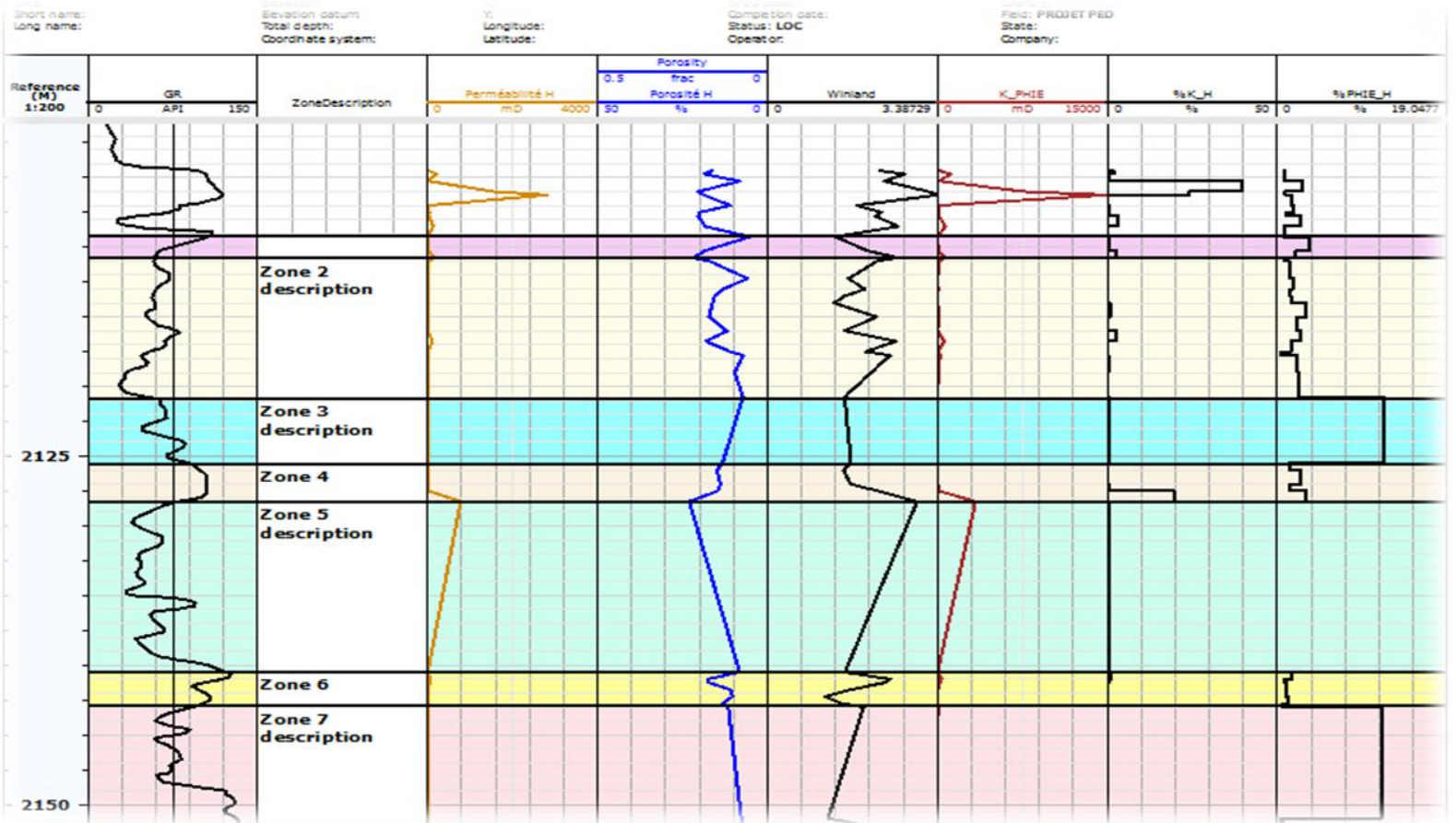

Figure 5: Well 11 Stratigraphic Flow Profile (SFP) 


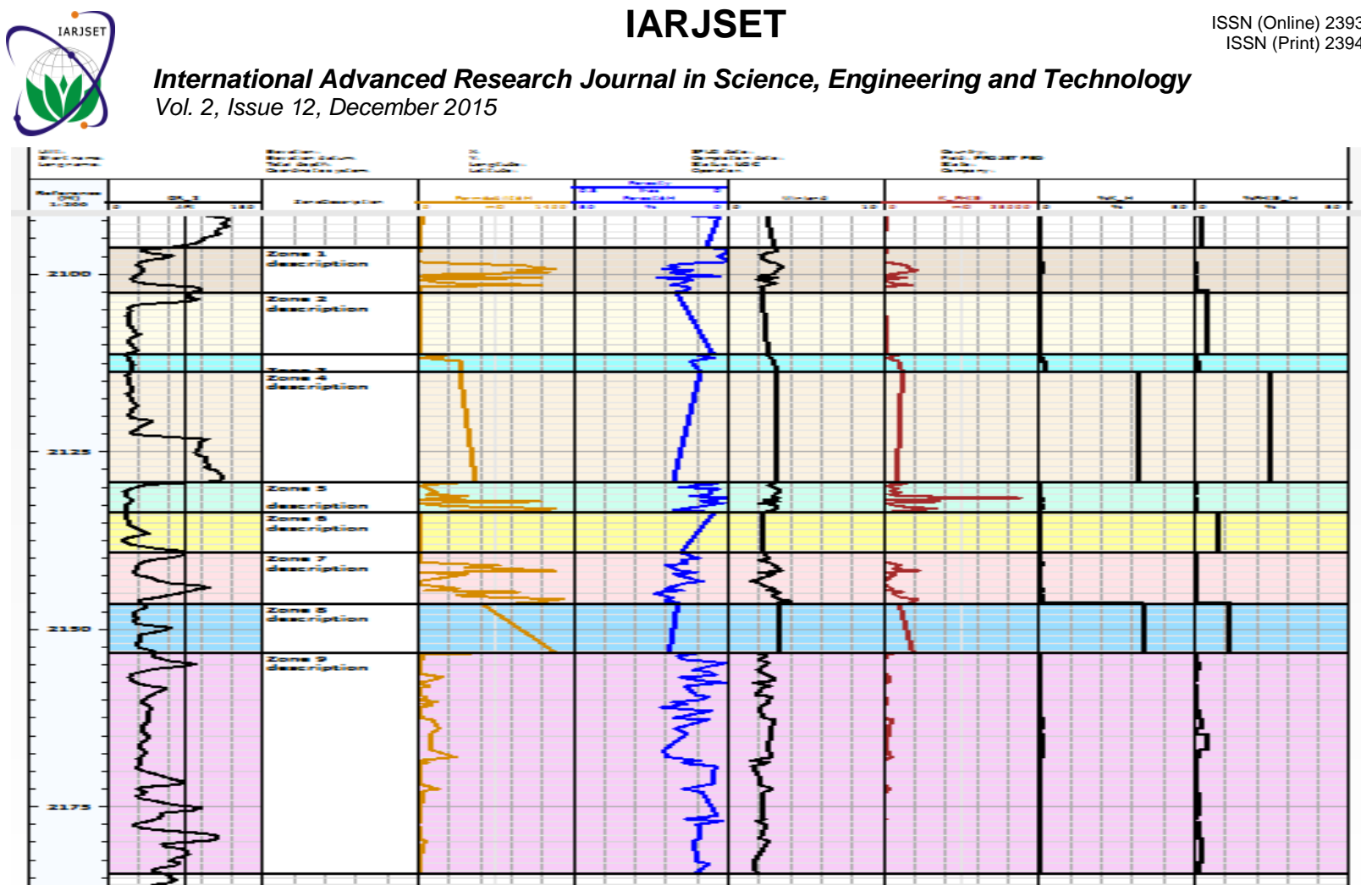

Figure 6: Well 12 Stratigraphic Flow Profile (SFP)

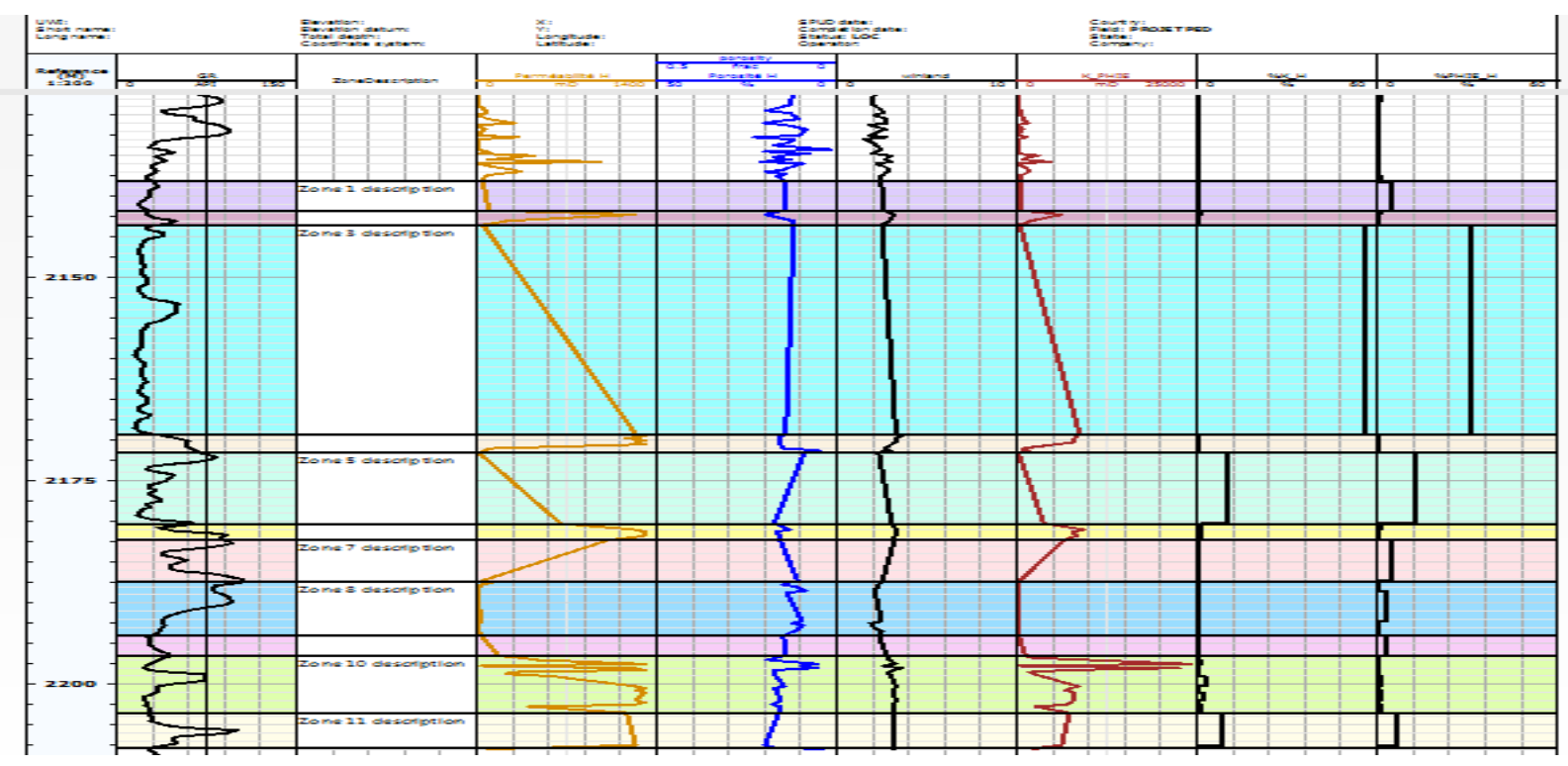

Figure 7: Well 13 Stratigraphic Flow Profile (SFP)

\section{Stratigraphic Modified Lorenz Plot (SMLP)}

Figure (8a, 9a, 10a, 11a), demonstrates a plot of an uninterpreted stratigraphic modified Lorenz plot (SMLP), the shape of this figures identify the flow performance of each particular well. Segments' having a steep slope indicates very high percentage of reservoir flow capacity with relation to the storage capacity, which also represents the highest processing speed referred to as speed zones.
Segments' having relatively flat slope indicates a very high percentage of reservoir storage capacity with respect to small amount of flow capacity also known as baffles (Zones that control formation fluid movement) and finally zones or segments that are neither flow or storage reservoir are referred to as barriers (seal to flow) such as faults. 

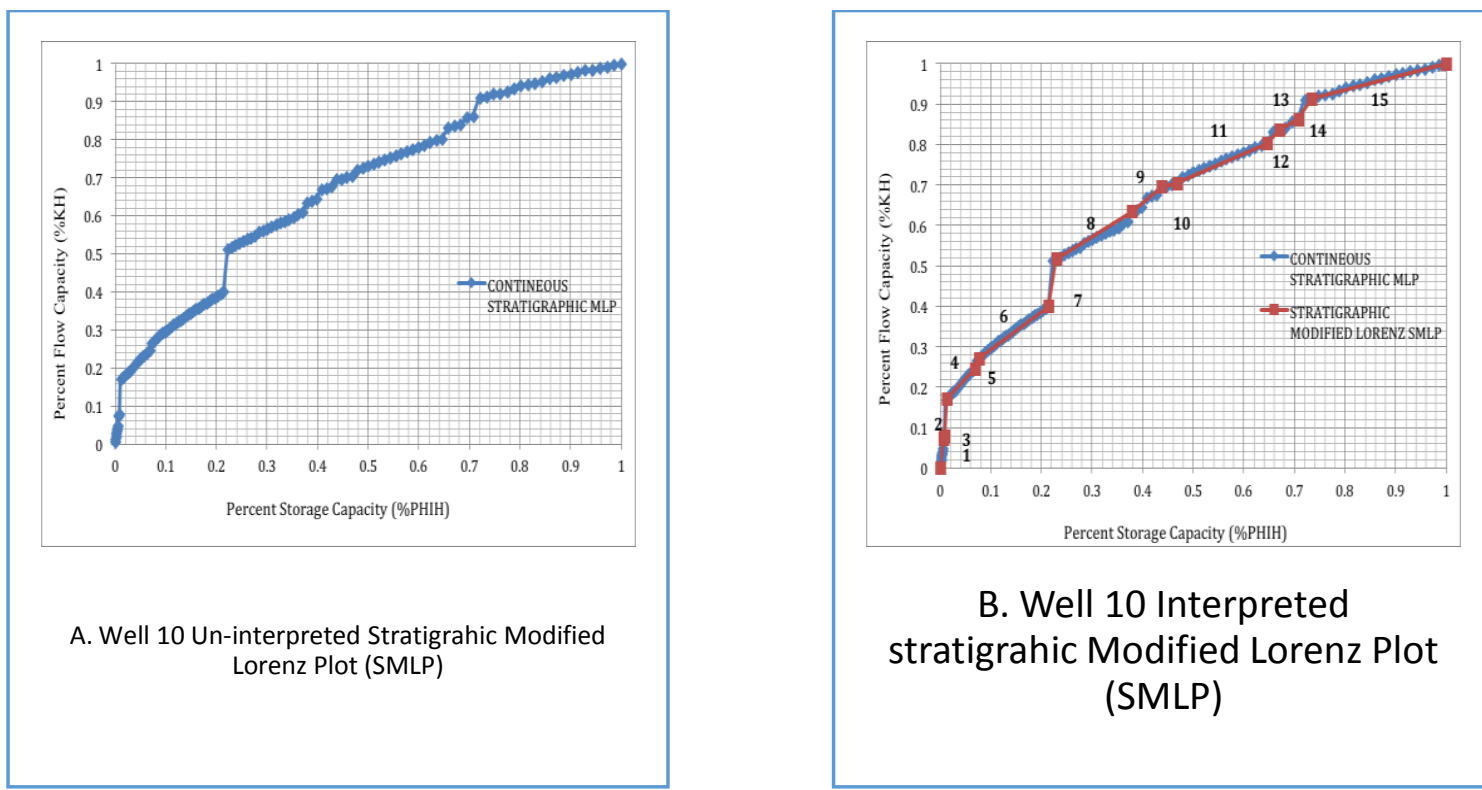

B. Well 10 Interpreted stratigrahic Modified Lorenz Plot (SMLP)

Figure 8: Stratigraphic Modified Lorenz Plot (a) Un-Interpreted (b) Interpreted

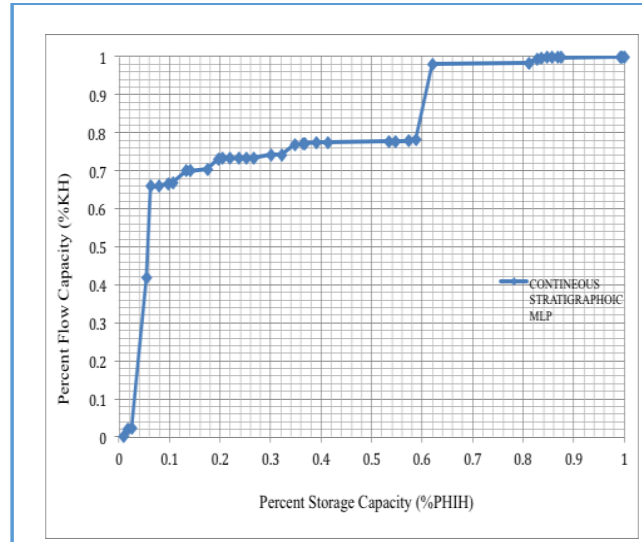

A. Well 11 Un-interpreted Stratigrahic Modified Lorenz Plot (SMLP)

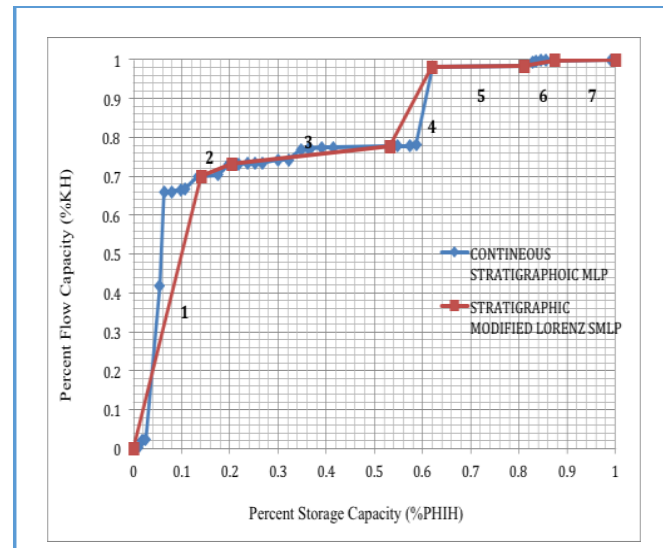

B. Well 11 Interpreted stratigrahic Modified Lorenz Plot (SMLP)

Figure 9: Stratigraphic Modified Lorenz Plot (a) Un-Interpreted (b) Interpreted 


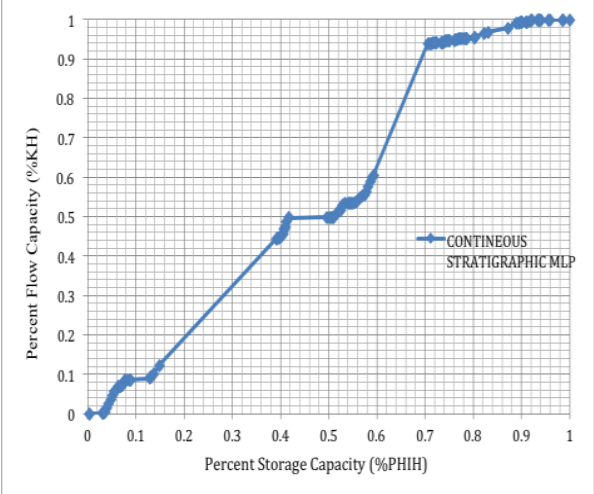

A. Well 12 Un-interpreted Stratigrahic Modified Lorenz Plot (SMLP)

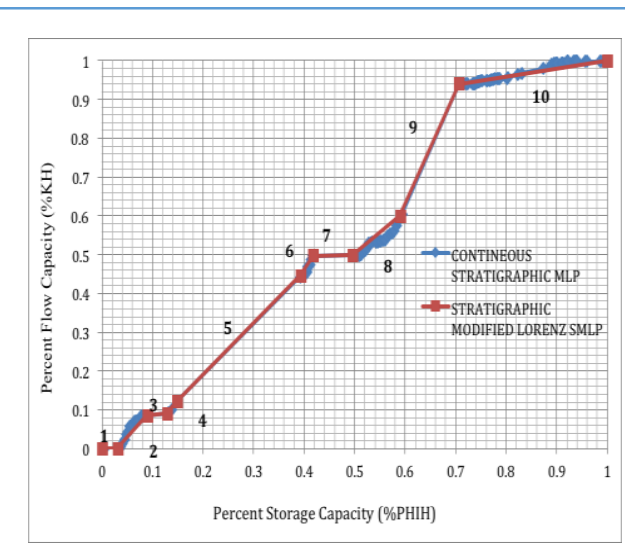

B. Well 12 Interpreted stratigrahic Modified Lorenz Plot (SMLP)

Figure 10: Stratigraphic Modified Lorenz Plot (a) Un-Interpreted (b) Interpreted

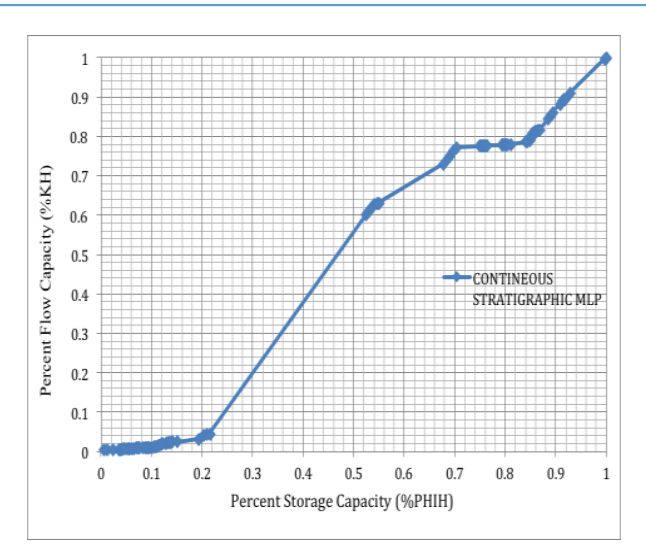

A. Well 13 Un-interpreted Stratigrahic Modified Lorenz Plot (SMLP)

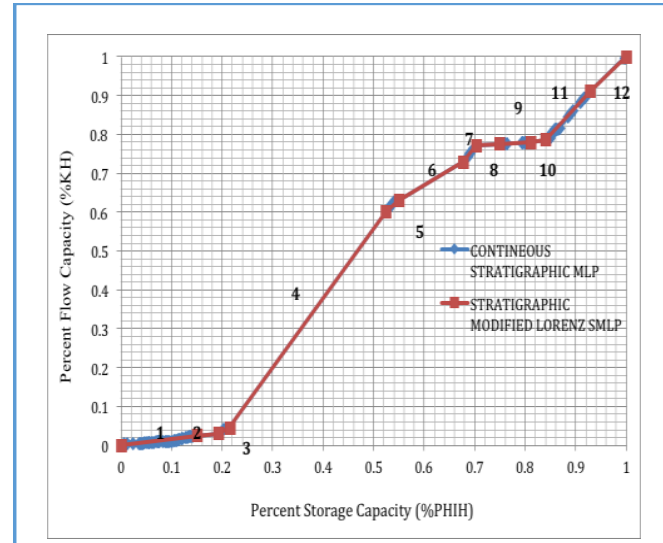

B. Well 13 Interpreted stratigrahic Modified Lorenz Plot (SMLP)

Figure 11: Stratigraphic Modified Lorenz Plot (a) Un-Interpreted (b) Interpreted

Figure $(8 \mathrm{~b}, 9 \mathrm{~b}, 10 \mathrm{~b}, 11 \mathrm{~b})$, demonstrates a plot of an baffles and barriers. It is important to know that the interpreted stratigraphic modified Lorenz plot (SMLP), the interpreted plot should retain similar shape to the undeveloped exploratory flow unit in figure $(4,5,6,7)$, are interpreted plot. The table below shows a well description used to compute the flow and storage capacity for each of the numbers of flow units for each well based on unit to interpreted the original Lorenz plot which provides interpreted (SMLP). an exceptional technique for recognizing speed zones, 
IARJSET

International Advanced Research Journal in Science, Engineering and Technology

Vol. 2, Issue 12, December 2015

\begin{tabular}{|c|c|c|c|c|}
\hline \multirow{2}{*}{ Wells } & \multirow{2}{*}{ No. of Flow Units } & \multicolumn{3}{|c|}{ Flow Units Characterizations } \\
\cline { 3 - 5 } & & Speed Zones & Baffles & Barriers \\
\hline Well 10 & 15 & $1,2,4,8$ & $3,5,6,7,15,12,13,14,11,10,9$ & 5,7 \\
\hline Well 11 & 7 & 1,4 & $2,3,6$ & $7,1,3$ \\
\hline Well 12 & 10 & $5,6,4,2,8$ & 10 & 8,9 \\
\hline Well 13 & 12 & $4,7,11,12$ & $6,3,10,1,2$ & \\
\hline
\end{tabular}

\section{Modified Lorenz Plot (MLP)}

Figure 12 demonstrates a plot of percent flow capacity versus percent flow capacity, for a definitive prediction of the flow unit performance. This is computed using the developed exploratory interval flow unit sorted and plotted in descending flow unit speed. In the figure, unit $(1,2,4$, 8) shows to be the speed zones that happen to have the highest flow unit speed (FUS) as shown in table 1. Unit $(3,5,6,7,15,12,13,14,11,10,9)$ illustrates to be baffles, which happen to have high storage capacity and lower flow capacity. This well does not have a seal.

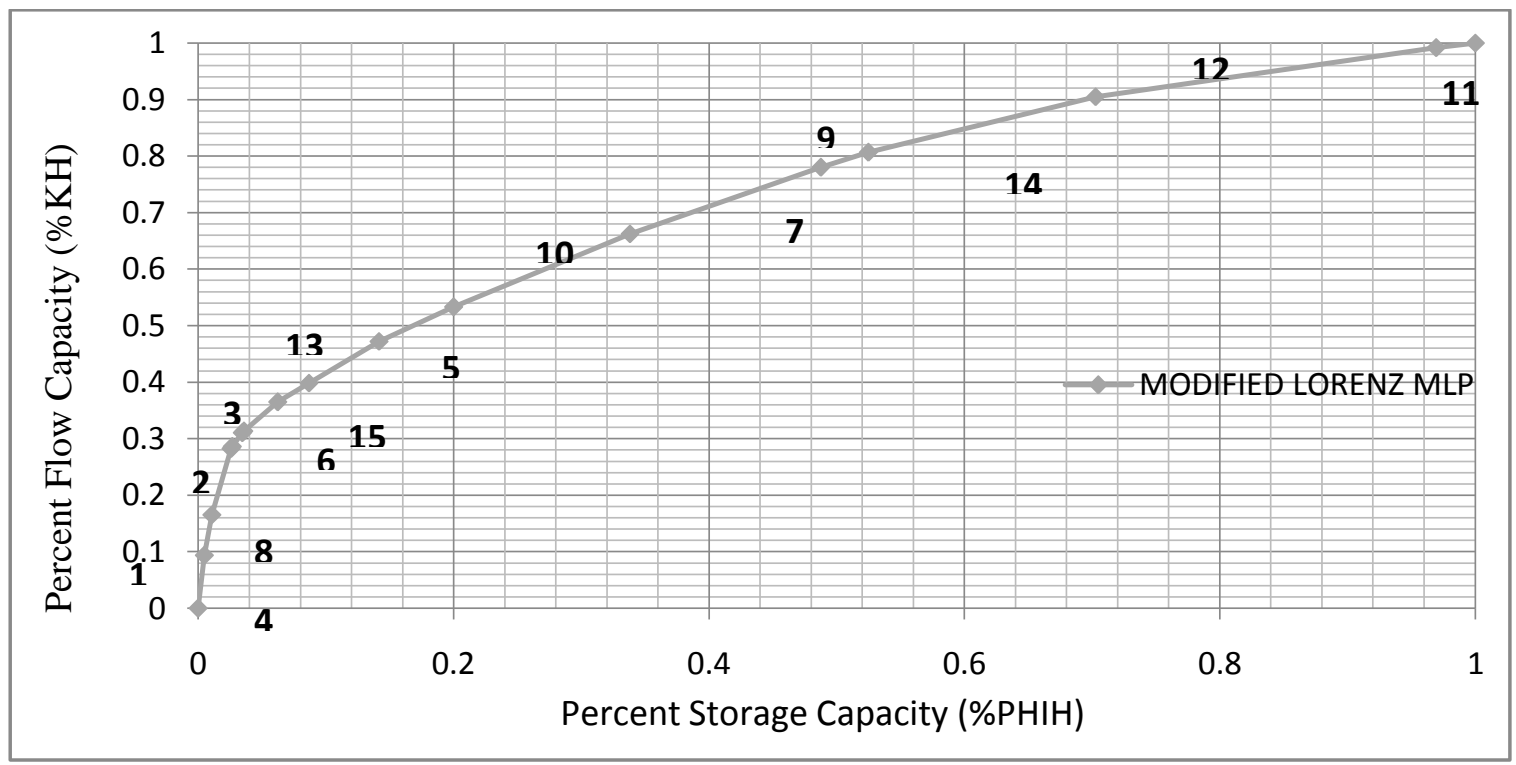

Figure 12: Well 10 Modified Lorenz Plot

Figure 13 demonstrates a plot of percent flow capacity highest flow unit speed (FUS) as shown in table 2 . Unit versus percent flow capacity, for a definitive prediction of $(2,3,6)$ illustrates to be baffles, which happen to have the flow unit performance. This is computed using the high storage capacity and lower flow capacity. Finally unit developed exploratory interval flow unit sorted and plotted $(5,7)$ illustrates a neither flow or storages capacity in descending flow unit speed. In the figure, unit $(1,4)$ indicating a seal.

shows to be the speed zones that happen to have the 
IARJSET

International Advanced Research Journal in Science, Engineering and Technology

Vol. 2, Issue 12, December 2015

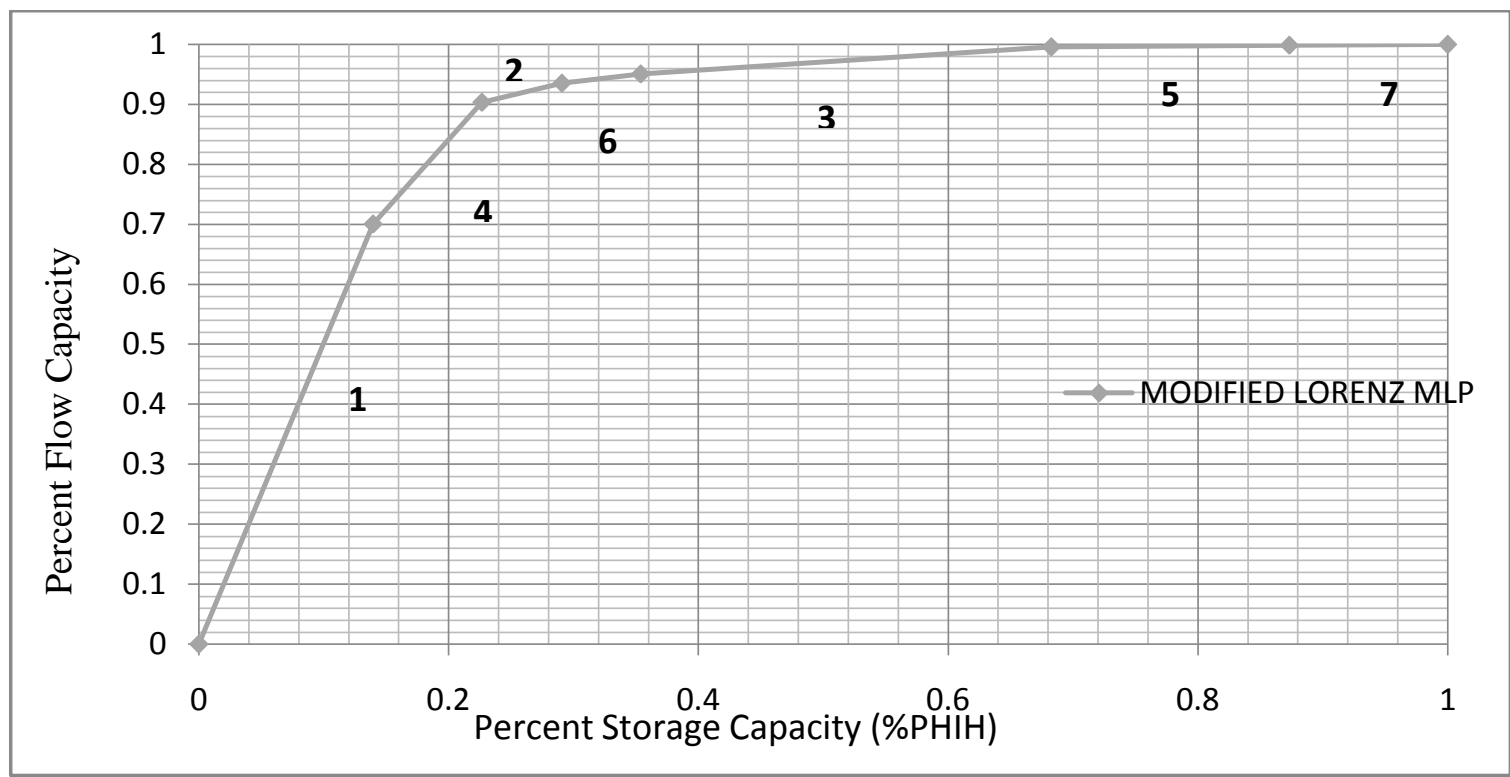

Figure 13: Well 11 Modified Lorenz Plot

Figure 14 demonstrates a plot of percent flow capacity highest flow unit speed (FUS) as shown in table 3 . Unit versus percent flow capacity, for a definitive prediction of (10) illustrates to be baffles, which happen to have high the flow unit performance. This is computed using the storage capacity and lower flow capacity. Finally unit ( 7 , developed exploratory interval flow unit sorted and plotted 1,3) illustrates a neither flow or storages capacity in descending flow unit speed. In the figure, unit $(5,6,4$, indicating a seal.

2,8 shows to be the speed zones that happen to have the

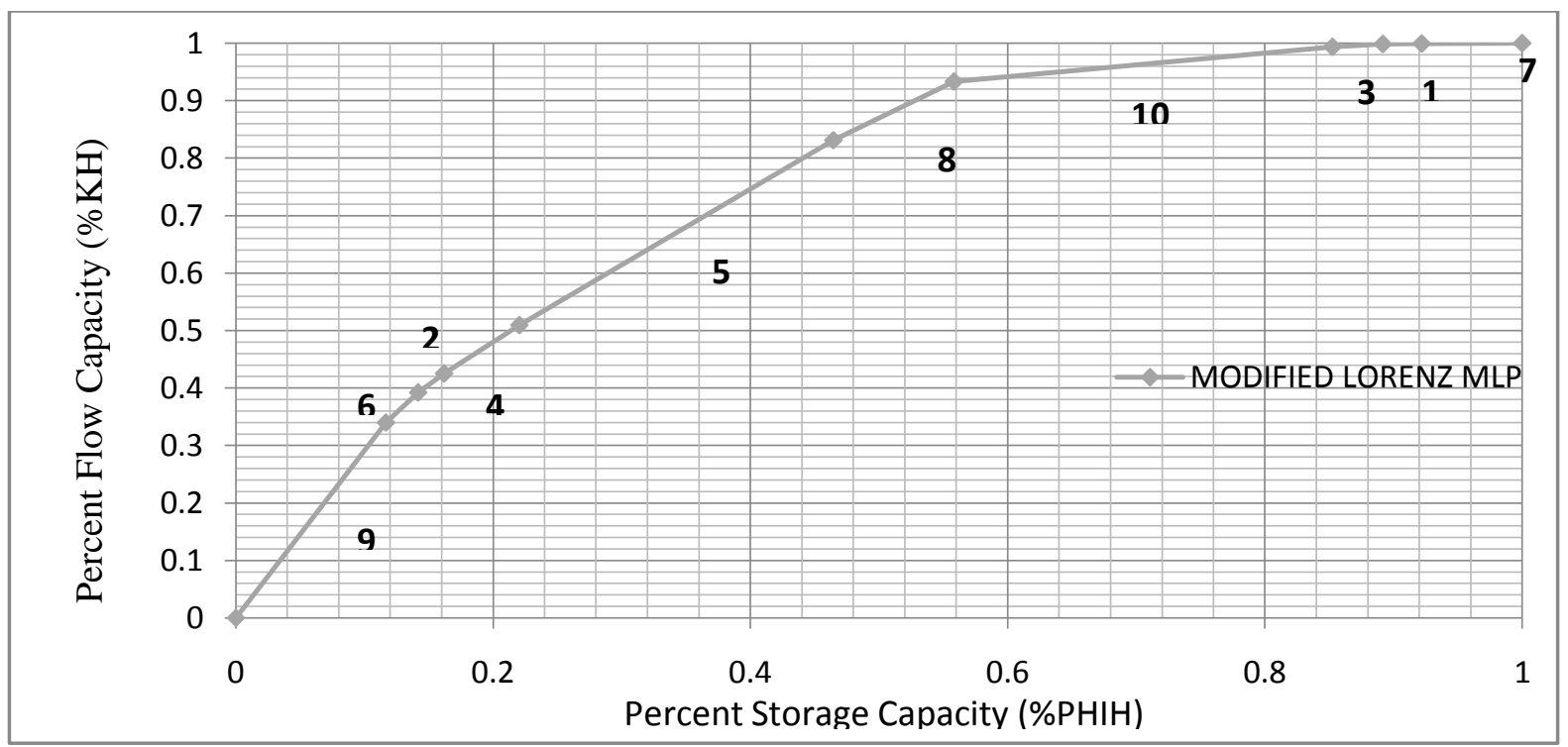

Figure 14: Well 12 Modified Lorenz Plot

Figure 15 demonstrates a plot of percent flow capacity highest flow unit speed (FUS) as shown in table 4 . Unit versus percent flow capacity, for a definitive prediction of $(6,3,10,1,2)$ illustrates to be baffles, which happen to the flow unit performance. This is computed using the have high storage capacity and lower flow capacity. developed exploratory interval flow unit sorted and plotted Finally, unit $(8,9)$ illustrates a neither flow or storages in descending flow unit speed. In the figure unit $(4,7,11$, capacity indicating a seal.

12) shows to be the speed zones that happen to have the 


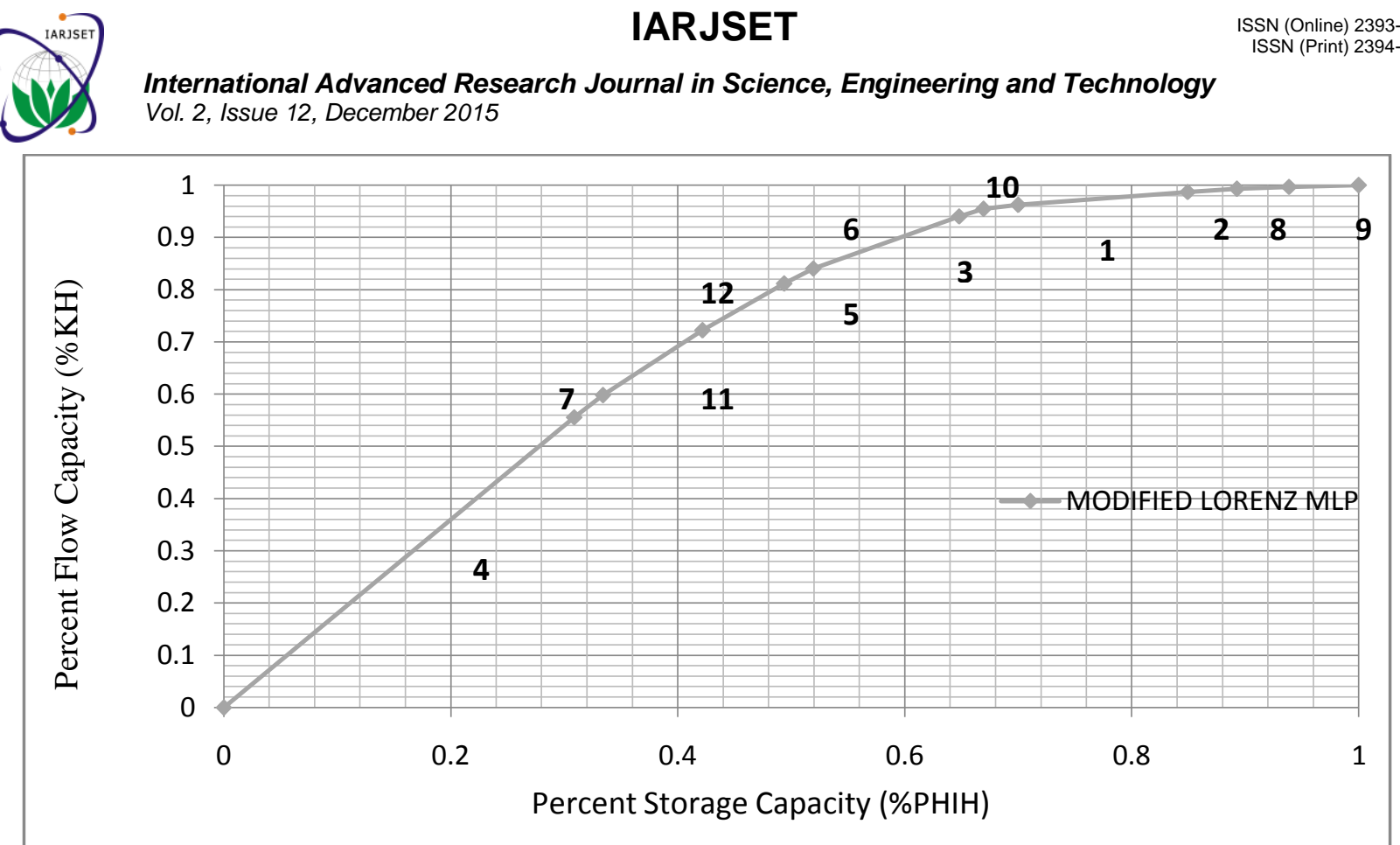

Figure 15: Well 13 Modified Lorenz Plot

\section{E.WELLS CORRELATION WITH TECHNIQUES}

Fig 16 shows well correlation, created using tech-log. This low Gamma ray and relatively high range of DRT, FZI figure illustrates zones classification based on GR reading and winland R35 that has better quality of fluids flow in indicating shale and sand stone zone with correlation to the pore spaces of the reservoir rock. While zone (1, 3, 7, Winland R35 method, FZI and DRT. This figure indicates 9) are shale zones, in relation to relatively high gamma ray 9 unit zones in this well having zone $(2,4,5,6,8)$ are sand and know as barriers (seals).

stone and proven to be a productive zones with relation to

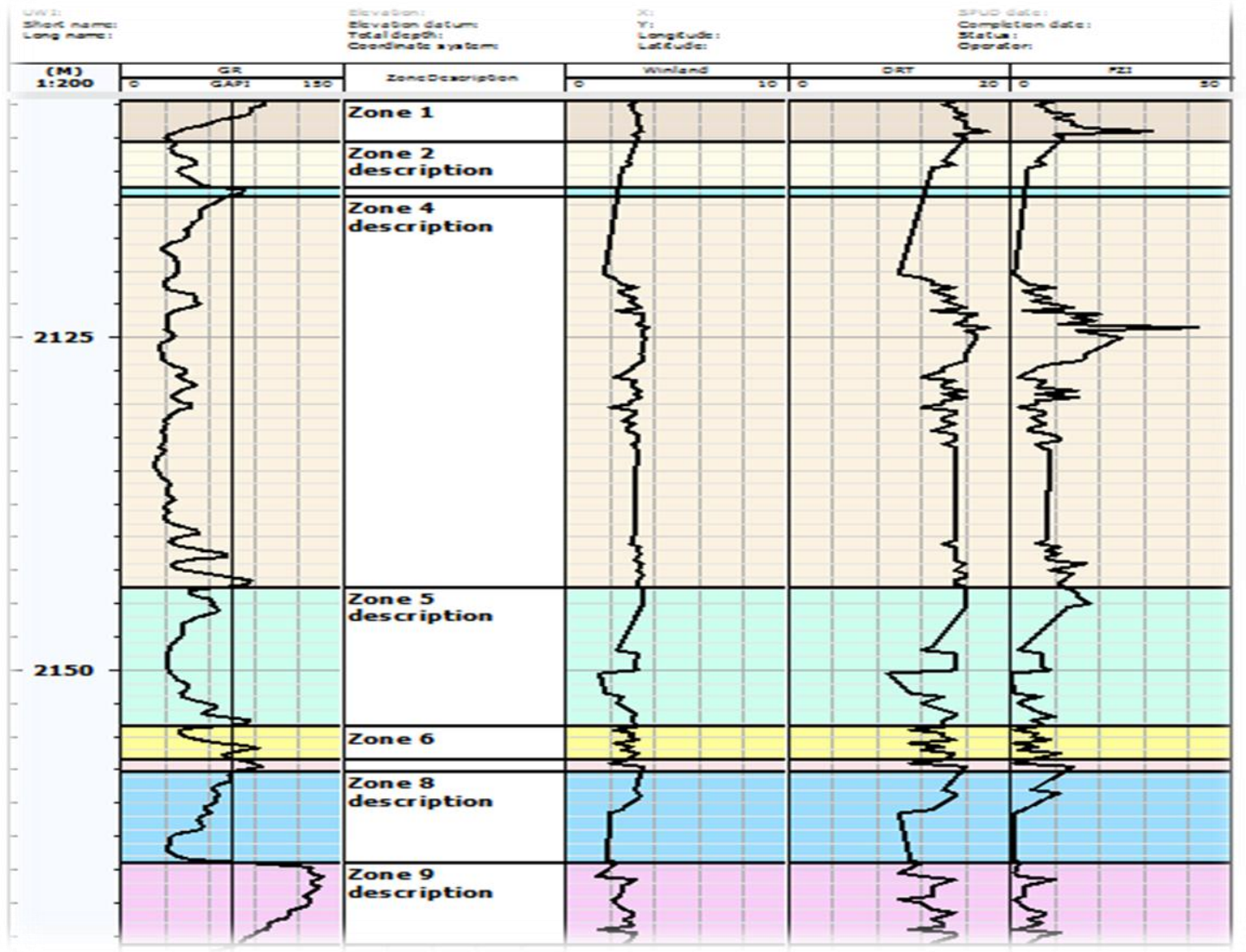

Figure 16: Well 10 Correlation with Techniques 
Fig 17 shows well correlation, created using tech-log. This low Gamma ray and relatively high range of DRT, FZI figure illustrates zones classification based on GR reading and winland R35 that has better quality of fluids flow in indicating shale and sand stone zone with correlation to the pore spaces of the reservoir rock. While zone (2, 4, 6, Winland R35 method, FZI and DRT. This figure indicates 8,9 ) are shale zones, in relation to relatively high gamma 9 unit zones in this well having zone $(1,3,5,7)$ are sand ray and know as barriers (seals).

stone and proven to be a productive zone with relation to

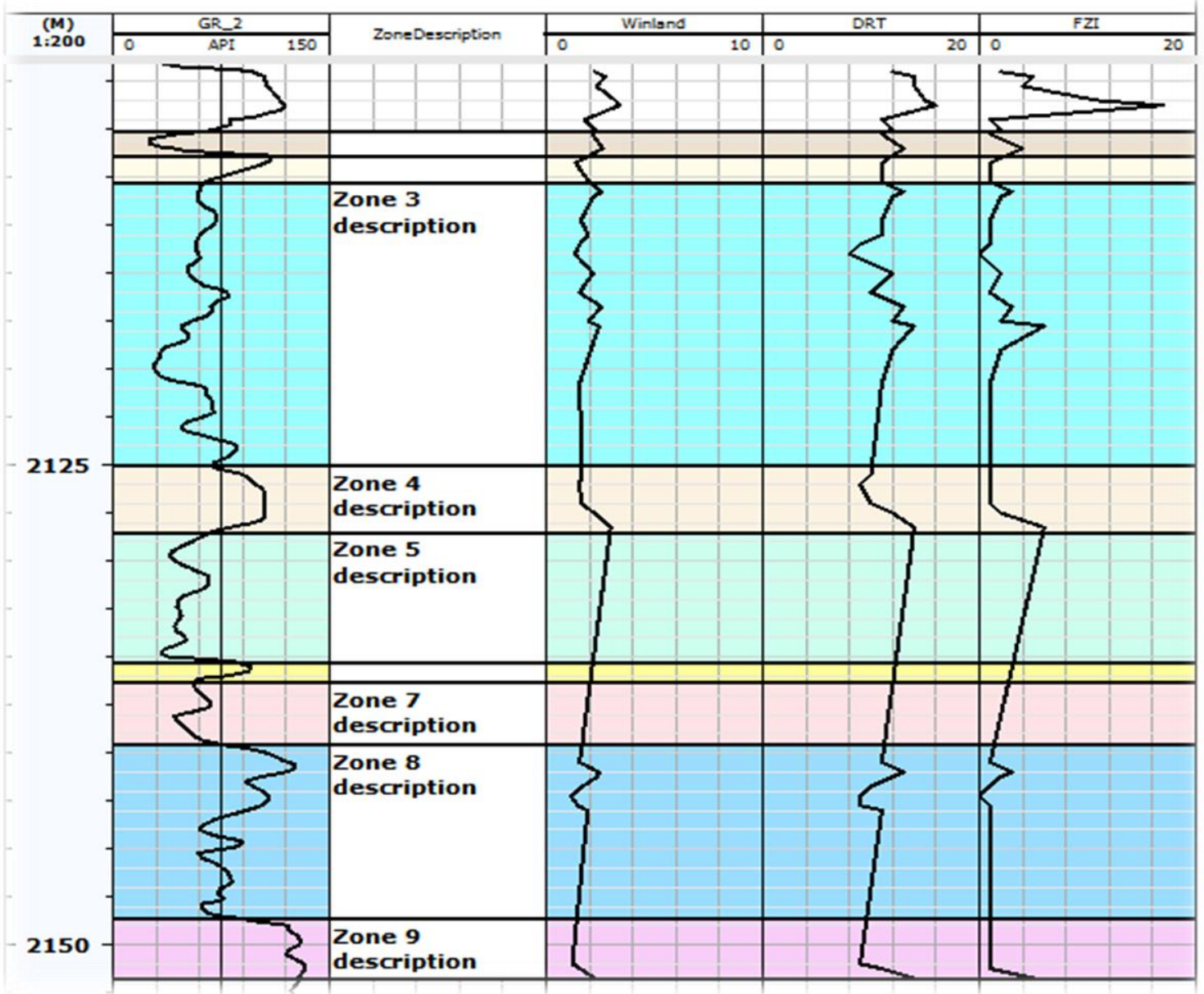

Figure 17: Well 11 Correlation with Techniques

Fig 18 shows well correlation, created using tech-log. This relation to low Gamma ray and relatively high range of figure illustrates zones classification based on GR reading DRT, FZI and winland R35 that has better quality of fluids indicating shale and sand stone zone with correlation to flow in the pore spaces of the reservoir rock. While zone Winland R35 method, FZI and DRT. This figure indicates $(2,4,6,8,10,12)$ are shale zones, in relation to relatively 13 unit zones in this well having zone $(1,3,5,7,9,11,13)$ high gamma ray and know as barriers (seals).

are sand stone and proven to be a productive zones with 
IARJSET

International Advanced Research Journal in Science, Engineering and Technology

Vol. 2, Issue 12, December 2015

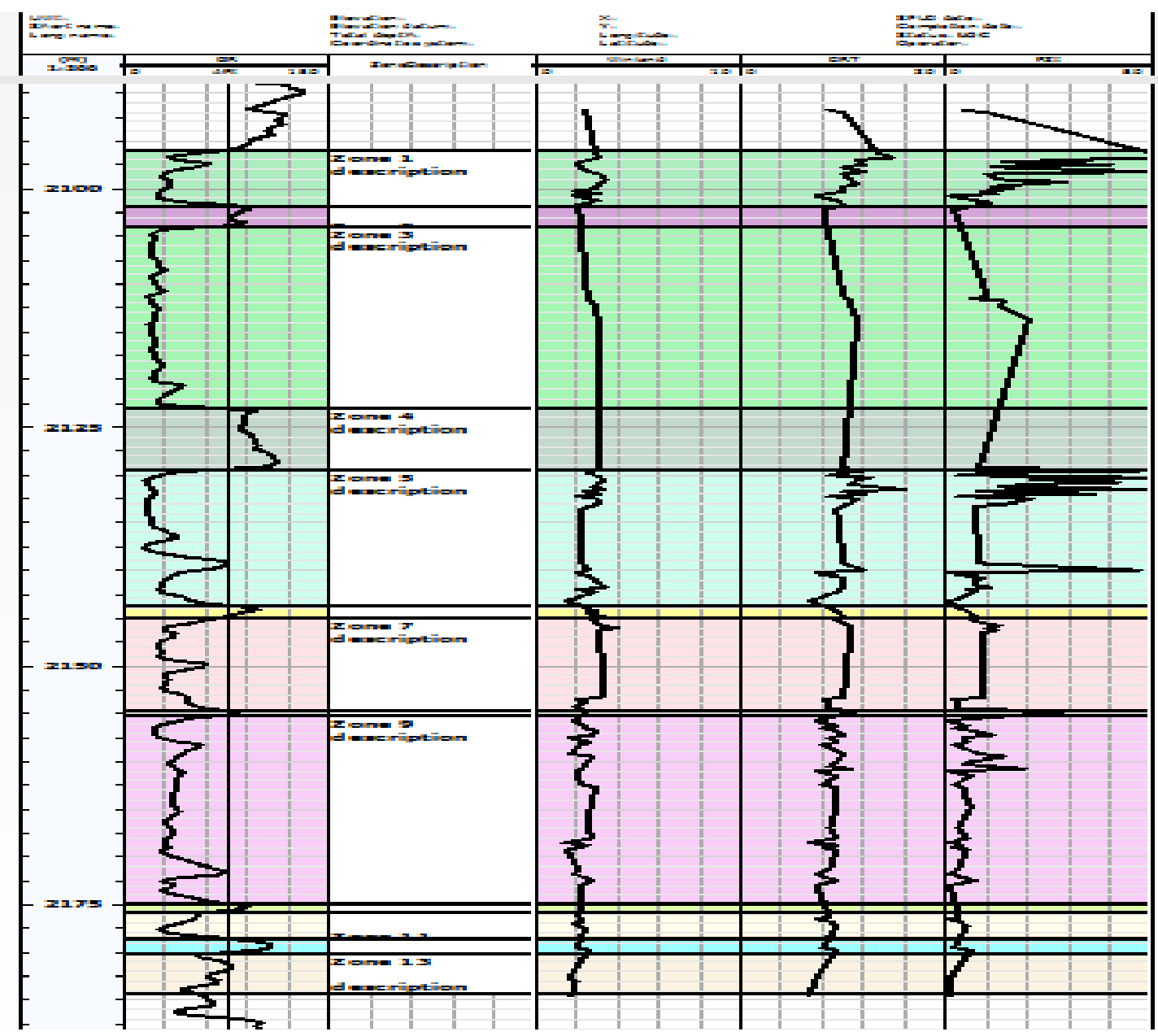

Figure 18: Well 12 Correlation with Techniques

Fig 19 shows well correlation, created using tech-log. This relation to low Gamma ray and relatively high range of figure illustrates zones classification based on GR reading DRT, FZI and winland R35 that has better quality of fluids indicating shale and sand stone zone with correlation to flow in the pore spaces of the reservoir rock. While zone Winland R35 method, FZI and DRT. This figure indicates $(1,3,5,7,9)$ are shale zones, in relation to relatively high 10 unit zones in this well having zone $(2,4,6,8,10)$ are gamma ray and know as barriers (seals). sand stone and proven to be a productive zones with 


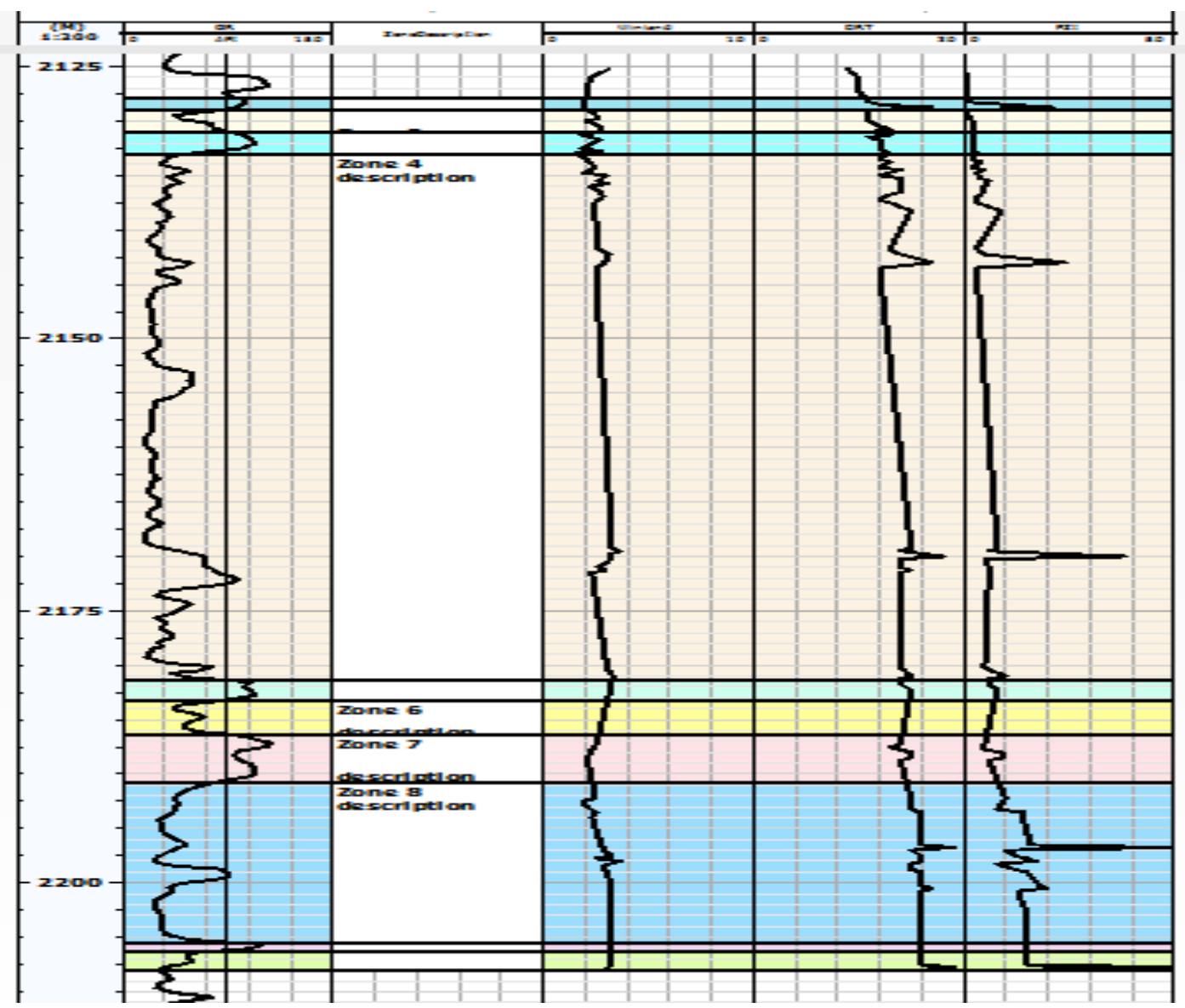

Figure 19: Well 13 Correlation with Techniques

\section{CONCLUSION}

Reservoir characterization is the first time step before any field development or any enhanced recovery project; efficient reservoir characterization provides a comprehensive description of the entire reservoir, which minimizes the failure of enhanced oil recovery and secondary recovery. The most common approaches for characterizing reservoir and analysing the reservoir rock type and flow units characterization were investigated in this research for a heterogeneous reservoir; including Flow Zone Indicator, Discrete Rock Type, and winland R35 method, storage capacity, flow capacity, stratigraphic flow profile (SFP), stratigraphic modified Lorenz plot (SMLP) and modified Lorenz plot (MLP). In accordance to the result the methods characterize the reservoir flows units, rock types, potential productive zones and barriers because it integrates and acknowledges various parameter that are regularly omitted. The geologic method is a major improvement over determining rock types and flow zone to identify barriers and potential productive zones; which provides a good image about the reservoir and creates a better descriptive reservoir model that can be applicable to any reservoir simulation.

\section{ACKNOWLEDGMENT}

The authors would like to extend their wholehearted gratitude to the British University in Egypt, Petroleum Engineering Dept. for supporting this research work.

\section{REFERENCES}

1. Abedini, A. (2011, november 2). Statistical Evaluation Of Reservoir Rock Type In A Carbonate Reservoir. SPE International. . Aldha, T. (2009). Carbonate Reservoir Charaterization Using Simultaneous Inversion, Batumerah Area, South Papua, Indonesia. UNIVERSITY OF INDONESIA, FACULTY OF MATHEMATICS AND NATURAL SCIENCES. Universitas Indonesia.

3. Amaefule O.jude, M. A. (1993, october 6). Enhanced Reservoir Description: Using Core And Log Data To Identify Hydraulic (flow) Units and Predict Permeability in Uncored intervals/wells. Archie, G. (1950). Introduction to petrophysics of reservoir rocks AAPG bulletin , 34, 934-961.

5. Carman, P. (1937). Fluid Flow through Granular Beds. 17.

6. Carman, P. (1939). Permeability of saturated sands soild and clays. Journal of Africultural science.

7. Choper, A. (1988). Reservoir Description Via Pulse. SPE internation.

8. Chopra A.K, S. M. (1987). Development of reservoir description to aid in desig of EOR projects. SPE.

9. Costa, A. (2006). Permeability-Porosity relationship: A reexamination of the Kozeny-Carman Equation Based on a fractal pore-space geometry assumption. Geophysical Research Letters, 5.

10. Donalson, D. T. (2004). Petrophysics. Theory and practice of measuring resrvoir rock and fluid transport properties (Vol. 2). Gulf Professional Publishing.

11. Dykstra, H. a. (1950). The prediction of oil recovery by water flood. Secondary Recovery of Oil in the United States.

12. Gunter G.W, P. J. (1997). Overview of an interagted process model to develop petrophysical based reservoir description. SPE.

13. Katz, A. a. (1986). Quantitative prediction of permeability in porous rock. Physical Review. 
International Advanced Research Journal in Science, Engineering and Technology

14. Kolodzie, S. (1980). Analysis of Pore Throat Size and Use of the Waxman-Smits Equation to Determine OOIP in Spindle Field. SPE INternational .

15. M. Shabaninejad, M. B. (2011, August 3). Rock Typing and Generalization Og Permeability-Porosity Relationship for an Inranian Carbonate Gas Reservoir. SPE International , 7.

16. Maghsood Abbaszadeh, H. F. (1996, December ). Permeability prediction by Hydraulic flow units -Theory and applications. SPE international

17. Mike Spearing, T. a. (2001). Review of the Winland R35 Method for net Pay Definiation and its appilicationin low permeability sands. Proceedings of the 2001 International Symposium of the Society of Core Analysts, paper SCA 2001-63. .

18. Nelson, P. (1994). Permeability-Porosity Relationships in sedimentary rocks. The log analyst, 38-62.

19. Nelson, P. H. (2005, November ). Permeability, Porosity and Porethroat size- A Three-Dimensional Perpective. Society of Petrophysicists and Well-Log Analysts, 46(6), 4.

20. Schmalz, J. P. (1950, July). The variation in water flood permance with variation inpermeability profilr. Producers Monthl

Table 1: Well 10 Flow Unit Speed

\begin{tabular}{|c|c|c|c|}
\hline $\begin{array}{c}\text { NO. of } \\
\text { Units }\end{array}$ & FUS & DKH & $\square$ PhiH \\
\hline 4 & 18.8111 & 0.0937 & 0.0049 \\
\hline 1 & 12.4940 & 0.0718 & 0.0057 \\
\hline 8 & 7.7833 & 0.1168 & 0.0150 \\
\hline 2 & 3.1653 & 0.0034 & 0.0011 \\
\hline 6 & 3.1272 & 0.0244 & 0.0078 \\
\hline 3 & 2.6098 & 0.0029 & 0.0011 \\
\hline 15 & 1.9455 & 0.0517 & 0.0266 \\
\hline 13 & 1.3700 & 0.0333 & 0.0243 \\
\hline 5 & 1.3382 & 0.0736 & 0.0550 \\
\hline 10 & 1.0436 & 0.0608 & 0.0582 \\
\hline 7 & 0.9380 & 0.1293 & 0.1379 \\
\hline 9 & 0.7874 & 0.1176 & 0.1494 \\
\hline 14 & 0.7052 & 0.0263 & 0.0373 \\
\hline 12 & 0.5538 & 0.0984 & 0.1777 \\
\hline 16 & 0.3244 & 0.0865 & 0.2667 \\
\hline 11 & 0.2792 & 0.0085 & 0.0306 \\
\hline
\end{tabular}

Table 2: Well 11 Flow Unit Speed

\begin{tabular}{|c|c|c|c|}
\hline $\begin{array}{c}\text { No. of } \\
\text { Units }\end{array}$ & FUS & DKH & $\square$ PhiH \\
\hline 1 & 5.0148 & 0.7003 & 0.1396 \\
\hline 4 & 2.3300 & 0.2030 & 0.0871 \\
\hline 2 & 0.5031 & 0.0321 & 0.0638 \\
\hline 6 & 0.2402 & 0.0151 & 0.0632 \\
\hline 3 & 0.1375 & 0.0452 & 0.3288 \\
\hline 5 & 0.0133 & 0.0025 & 0.1904 \\
\hline 7 & 0.0118 & 0.0015 & 0.1268 \\
\hline
\end{tabular}

Table 3: Well 12 Flow Unit Speed

\begin{tabular}{|c|c|c|c|}
\hline $\begin{array}{c}\text { No. of } \\
\text { Units }\end{array}$ & FUS & DKH & $\square$ PhiH \\
\hline 9 & 2.9164 & 0.3401 & 0.1166 \\
\hline 6 & 2.0803 & 0.0519 & 0.0249 \\
\hline 4 & 1.6234 & 0.0330 & 0.0203 \\
\hline 2 & 1.4453 & 0.0843 & 0.0583 \\
\hline 5 & 1.3200 & 0.3222 & 0.2441 \\
\hline 8 & 1.0818 & 0.1016 & 0.0939 \\
\hline 10 & 0.2048 & 0.0602 & 0.2942 \\
\hline 3 & 0.1292 & 0.0050 & 0.0391 \\
\hline 1 & 0.0260 & 0.0007 & 0.0301 \\
\hline 7 & 0.0069 & 0.0005 & 0.0781 \\
\hline
\end{tabular}

Table 4: Well 13 Flow Unit Speed

\begin{tabular}{|c|c|c|c|}
\hline $\begin{array}{c}\text { No. of } \\
\text { Units }\end{array}$ & FUS & DKH & $\square$ PhiH \\
\hline 4 & 1.8000 & 0.5557 & 0.3087 \\
\hline 7 & 1.6726 & 0.0422 & 0.0252 \\
\hline 11 & 1.4164 & 0.1243 & 0.0877 \\
\hline 12 & 1.2400 & 0.0892 & 0.0720 \\
\hline 5 & 1.1269 & 0.0289 & 0.0256 \\
\hline 6 & 0.7752 & 0.0996 & 0.1285 \\
\hline 3 & 0.6805 & 0.0144 & 0.0212 \\
\hline 10 & 0.2438 & 0.0074 & 0.0306 \\
\hline 1 & 0.1671 & 0.0249 & 0.1493 \\
\hline 2 & 0.1303 & 0.0056 & 0.0434 \\
\hline 8 & 0.0859 & 0.0039 & 0.0460 \\
\hline 9 & 0.0527 & 0.0032 & 0.0613 \\
\hline
\end{tabular}

